\title{
AN AERIAL RADIOLOGICAL SURVEY OF THE TRINITY FALLOUT AREA
}

\author{
WHITE SANDS MISSILE RANGE, NEW MEXICO
}

DATE OF SURVEY: MAY-JUNE 1992

A. E. Fritzsche

Project Scientist

REVIEWED BY

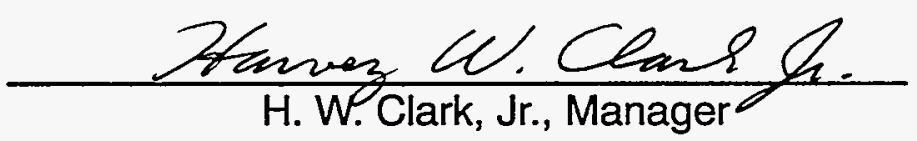

Radiation Science Section

This Document is UNCLASSIFIED

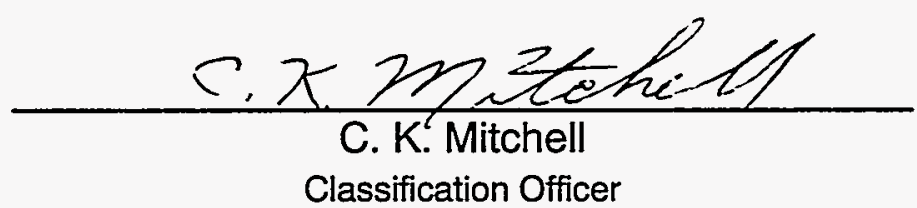

This work was performed by EG\&G/EM for the United States Department of Energy under Contract Number DE-AC08-93NV11265. 


\section{DISCLAIMER}

This report was prepared as an account of work sponsored by an agency of the United States Government. Neither the United States Government nor any agency thereof, nor any of their employees, make any warranty, express or implied, or assumes any legal liability or responsibility for the accuracy, completeness, or usefulness of any information, apparatus, product, or process disclosed, or represents that its use would not infringe privately owned rights. Reference herein to any specific commercial product, process, or service by trade name, trademark, manufacturer, or otherwise does not necessarily constitute or imply its endorsement, recommendation, or favoring by the United States Government or any agency thereof. The views and opinions of authors expressed herein do not necessarily state or reflect those of the United States Government or any agency thereof. 


\section{DISCLAIMER}

Portions of this document may be illegible in electronic image products. Images are produced from the best available original document. 


\section{ABSTRACT}

An aerial gamma survey was conducted during May and June of 1992 to define the Trinity fallout field, which lies primarily in the White Sands Missile Range in the state of New Mexico. The field was mapped almost entirely from the gamma ray emissions of cesium-137 ( $\left.{ }^{137} \mathrm{Cs}\right)$, a fission product. The field, as measured, extends from Trinity ground zero, over the Oscura Mountains, across the Chupadera Mesa, and thence past Cedarvale, New Mexico, a distance of more than 100 kilometers. An estimate of ${ }^{137} \mathrm{Cs}$ activity inventory is $100 \mathrm{Ci}$ in an area covering 1,400 square kilometers. Another isotope, europium-152, is significant at ground zero. $A{ }^{137} \mathrm{Cs}$ concentration contour plot overlaid on a U. S. Geological Survey map indicates the location and intensity of the fallout field. A contour map of terrestrial exposure rate is presented in a similar fashion. 


\section{CONTENTS}

Abstract

\section{Sections}

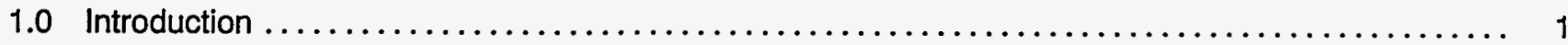

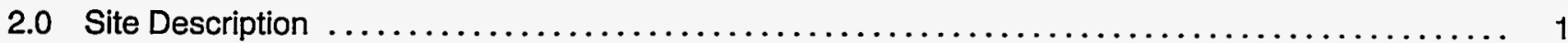

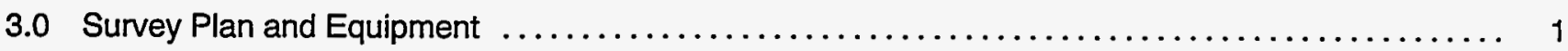

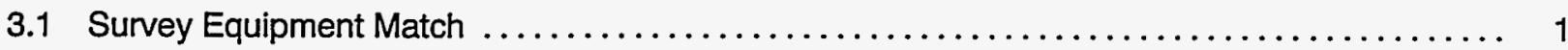

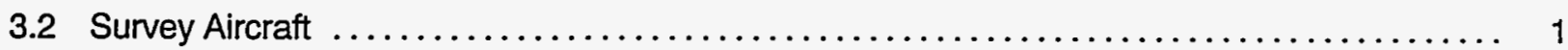

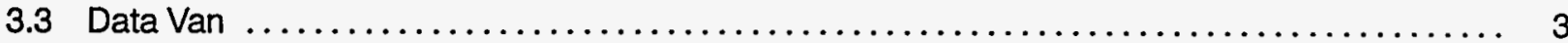

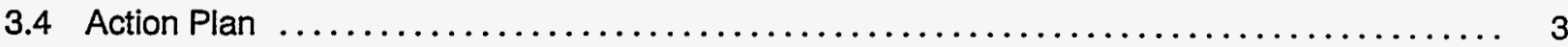

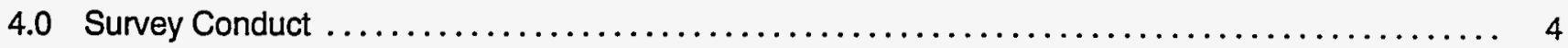

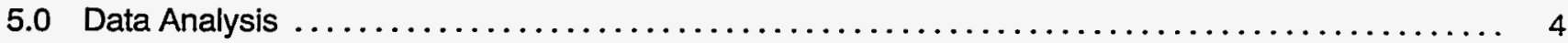

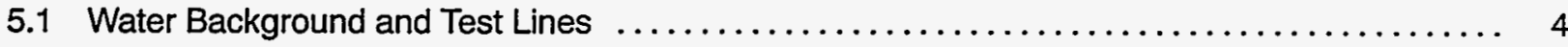

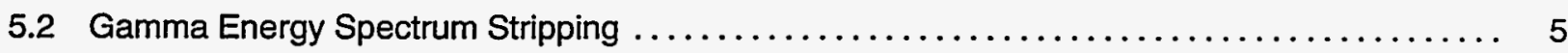

5.3 Counting Statistics and Detection Limit $\ldots \ldots \ldots \ldots \ldots \ldots \ldots \ldots \ldots \ldots \ldots \ldots \ldots \ldots \ldots \ldots \ldots \ldots$

5.4 Map Verification with Energy Spectra $\ldots \ldots \ldots \ldots \ldots \ldots \ldots \ldots \ldots \ldots \ldots \ldots \ldots \ldots \ldots \ldots \ldots \ldots \ldots \ldots$

5.5 Exposure and Isotope Concentration Estimates $\ldots \ldots \ldots \ldots \ldots \ldots \ldots \ldots \ldots \ldots \ldots \ldots \ldots$

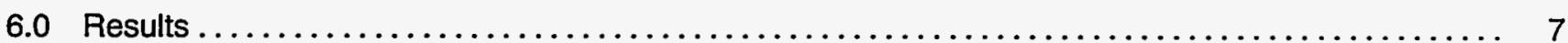

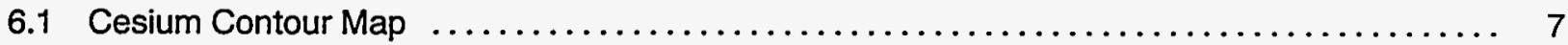

6.1.1 General Characteristics ................................... 7

6.1.2 Cesium Concentration ...................................... 9

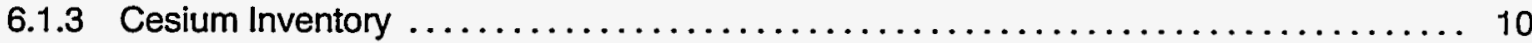

6.2 Aerial and Ground-Based Exposure Measurements $\ldots \ldots \ldots \ldots \ldots \ldots \ldots \ldots \ldots \ldots \ldots 10$

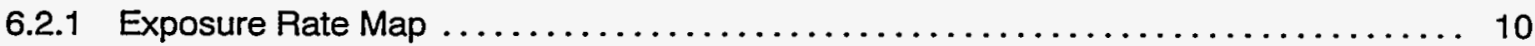

6.2.2 Ground-Based Exposure and Concentration Results $\ldots \ldots \ldots \ldots \ldots \ldots \ldots \ldots \ldots \ldots$

6.2.3 Cesium-137 Exposure Rates ................................. 11

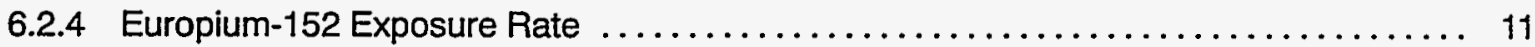

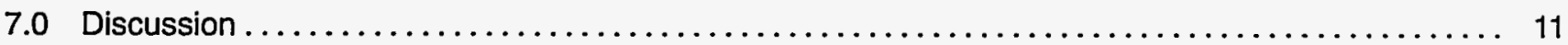

\section{Figures}

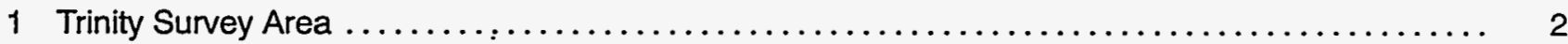




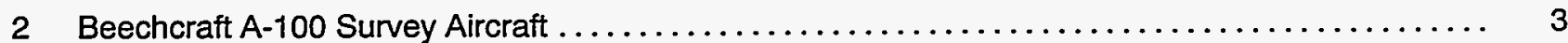

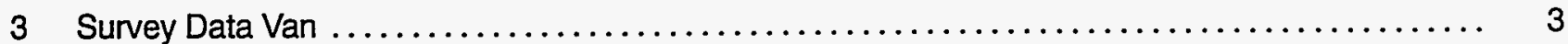

4 Cesium-137 Contour Map of Trinity Fallout $\ldots \ldots \ldots \ldots \ldots \ldots \ldots \ldots \ldots \ldots \ldots \ldots \ldots \ldots \ldots \ldots \ldots \ldots \ldots$

5 Total Gamma Energy Spectrum over Chupadera Mesa $\ldots \ldots \ldots \ldots \ldots \ldots \ldots \ldots \ldots \ldots \ldots . \ldots$

6 Cesium-137 Gamma Energy Spectrum over Chupadera Mesa $\ldots \ldots \ldots \ldots \ldots \ldots \ldots \ldots \ldots \ldots . . . . \ldots$

7 Terrestrial Gamma Exposure Rates in the Trinity Fallout Area $\ldots \ldots \ldots \ldots \ldots \ldots \ldots \ldots \ldots \ldots .12$

8 Terrestrial Gamma Energy Spectrum over Trinity Ground Zero $\ldots \ldots \ldots \ldots \ldots \ldots \ldots \ldots \ldots \ldots$

B.1 Energy Window Set for Cesium-137 Photopeak Extraction $\ldots \ldots \ldots \ldots \ldots \ldots \ldots \ldots \ldots \ldots \ldots$

\section{Tables}

1 Aerial Count Rate Conversions to Cesium-137 Concentration

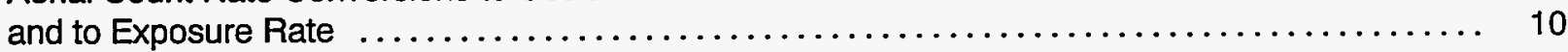

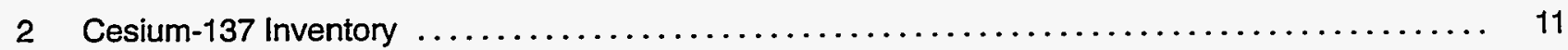

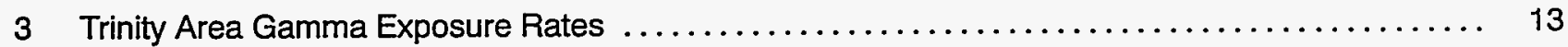

4 Isotope Concentrations and Soil Moisture Obtained from Soil Samples $\ldots \ldots \ldots \ldots \ldots \ldots \ldots \ldots$. 13

5 Aerial/Soil Sample Cesium-137 Concentration Comparison $\ldots \ldots \ldots \ldots \ldots \ldots \ldots \ldots \ldots \ldots \ldots \ldots$

\section{Appendices}

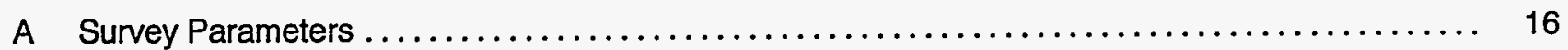

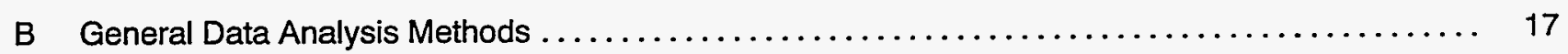

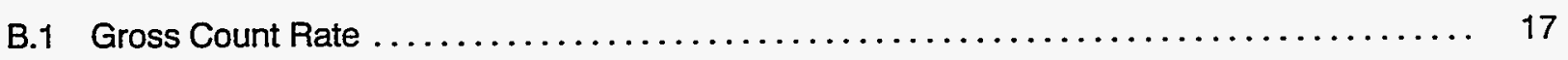

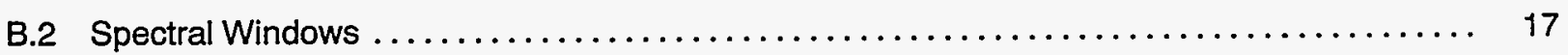

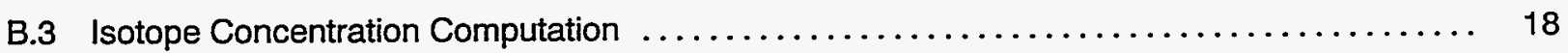

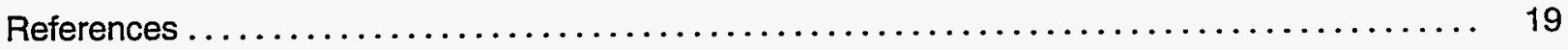




\subsection{INTRODUCTION}

Trinity, the first nuclear explosion test, was detonated at 0530 on July 16,1945 and was the culmination of the Manhattan Project. ${ }^{1}$ The radioactive remnants, both from neutron activation and fission products, have been investigated by the Los Alamos National Laboratory ${ }^{2}$ (LANL), the Department of Energy ${ }^{3}$ (DOE), and the Environmental Protection Agency ${ }^{4}$ (EPA). The initial and subsequent ground-based gamma exposure measurements show that the measurable fallout pattern extends more than $100 \mathrm{~km}$ from ground zero (GZ). The large size of the fallout field and the rugged and rather remote terrain suggested the use of DOE's Aerial Measuring System capability to complement the ground-based measurements.

The Remote Sensing Laboratory (RSL), operated by EG\&G Energy Measurements (EG\&G/ EM) for DOE, conducted an aerial gamma survey during May and June of 1992. The gamma data were reduced to a map of the Trinity fallout pattern as well as a map of the external exposure rates in that area.

\subsection{SITE DESCRIPTION}

The Trinity site is located on the White Sands Missile Range (WSMR) in the state of New Mexico. Ground zero, coordinates $\mathrm{N} 33^{\circ} 40.52^{\prime}, \mathrm{W} 106^{\circ} 29.48^{\prime}$, is 161 $\mathrm{km}$ (100 mi) south of Albuquerque and $56 \mathrm{~km}$ (35 mi) southeast of Socorro, New Mexico. The base of operations was located at Alamogordo, New Mexico, $100 \mathrm{~km}(62 \mathrm{mi})$ south of $\mathrm{GZ}$. The area surveyed (Figure 1) extends from $6 \mathrm{~km}$ (4 mi) south of $G Z$ to 110 $\mathrm{km}(68 \mathrm{mi})$ in the northeast direction, which was the direction of the primary fallout cloud path. About two thirds of the survey (including GZ) is in Socorro County with the remaining one third in the counties of Lincoln and Torrance. The area includes the Oscura Mountains, $8 \mathrm{~km}(5 \mathrm{mi})$ to the east of $\mathrm{GZ}$, and Chupadera Mesa, from 8 to $48 \mathrm{~km}$ ( 5 to $30 \mathrm{mi}$ ) northeast of GZ. The area beyond Chupadera Mesa is dominated by Gallinas Peak, $90 \mathrm{~km}$ ( $56 \mathrm{mi}$ ) from GZ. The survey area is sparsely populated, consisting mostly of desert and mountains. A few small villages are in the survey area: Bingham, Claunch, and Cedarvale. Ranching is the primary private land use outside the WSMR.

\subsection{SURVEY PLAN AND EQUIPMENT}

\subsection{Survey Equipment Match}

Comprehensive reports show the location and isotope concentration levels of the Trinity fallout field as measured from the ground ${ }^{2}$ and as predicted from the zero time winds ${ }^{3}$ and early time ground monitoring data. ${ }^{3}$ These reports suggested that a survey area of some $4,000 \mathrm{~km}^{2}\left(1,560 \mathrm{mi}^{2}\right)$ extending $100 \mathrm{~km}(62$ mi) northeast of ground zero might be necessary.

Operational and gamma sensitivity parameters are well known for DOE aircraft and gamma data systems. However, a new navigation system was under test that would substantially aid the Trinity survey. This system, called the Global Positioning System (GPS), has worldwide coverage, whereas the longused ultrahigh frequency ranging system (URS) has limited coverage and range, especially in mountainous areas. The URS system was also fielded in case difficulties with the GPS system required a fallback to a previous navigation system.

The DOE Beechcraft A-100 fixed-wing aircraft was chosen for the survey to accommodate the large, remote and mountainous area. The MesserschmittBolkow-Blohm BO-105 helicopter, commonly used for gamma surveys, was not chosen because the time available per helicopter flight was too short to expeditiously cover the large survey area.

Descriptions of the survey aircraft system and the data van system are given in the following two sections. The survey parameters may be found in Appen$\operatorname{dix} A$.

\subsection{Survey Aircraft}

A Beechcraft A-100 fixed-wing aircraft was used as the aerial platform (Figure 2). The aircraft carried four detector pods, each containing two $4-\times 4-\times 16$-in log-type $\mathrm{Nal}(\mathrm{Tl})$ detectors. Gamma ray signals from the Nal detectors were routed to the Radiation and Environmental Data Acquisition and Recorder IV (REDAR IV) system for pulse height analysis and storage on magnetic tape. Pressure, temperature, GPS data, and radar altitude transducer data were also acquired and stored by REDAR. Gamma ray energy spectra and the total count rates were displayed on a CRT as they were being acquired so that 


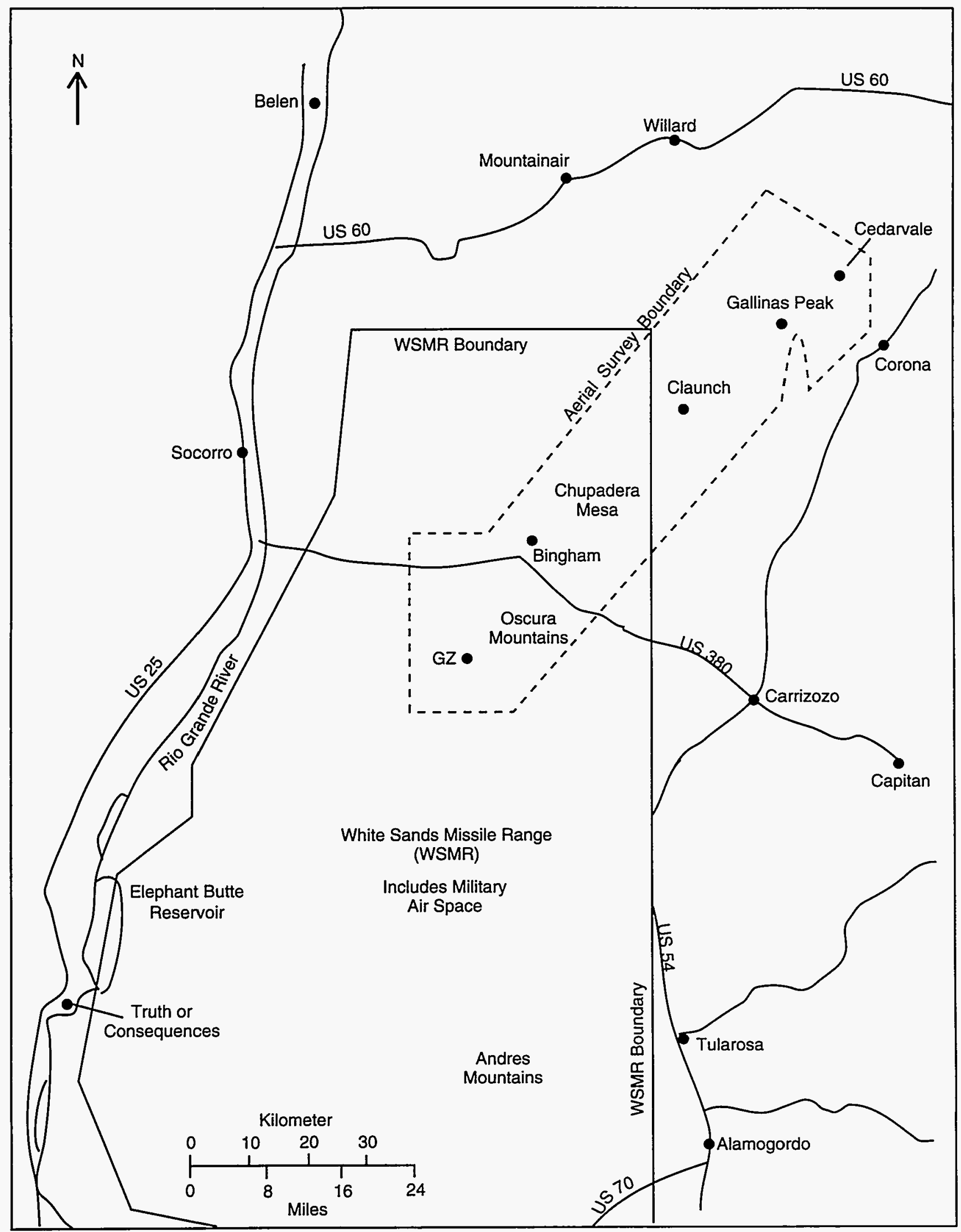

FIGURE 1. TRINITY SURVEY AREA 
the system operator could monitor them. The other two crew members were responsible for flying the aircraft.

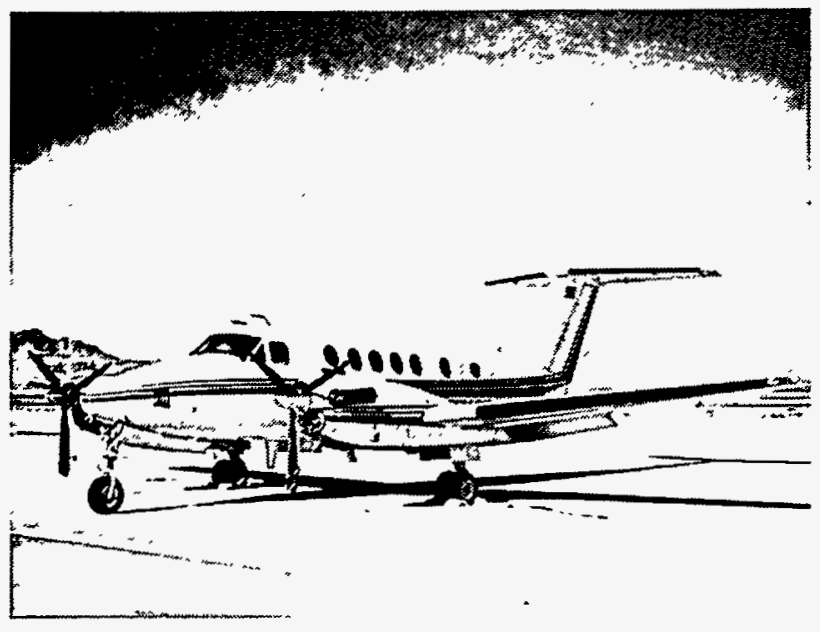

FIGURE 2. BEECHCRAFT A-100 SURVEY AIRCRAFT

\subsection{Data Van}

A computer-based system (Figure 3 ), housed in a van, was used during the survey to evaluate the data immediately following each survey flight. The system contains hardware and software that operate on the stored data. The data analyst can plot gamma ray spectra from any portion of the gamma survey as well as contours of constant count rates scaled to a map or photograph. In this manner, the intensity and location of the isotope emitters can be identified within hours of each survey flight.

\subsection{Action Plan}

The actions required to prepare for, accomplish, and document the Trinity aerial survey were:

1. Configure the DOE A-100 aircraft to accept both GPS (satellite) and URS (ground-based) guidance. Test the A-100 aircraft for both guidance systems.

2. Test the A-100 gamma system for sensitivity to point sources and sensitivity to the documented Lake Mead Test Line (LMTL).

3. Test the A-100 aircraft over the Trinity fallout field as a presurvey mission. Since WSMR is within A-100 flight range of Las Vegas, Nevada, some technical questions could be

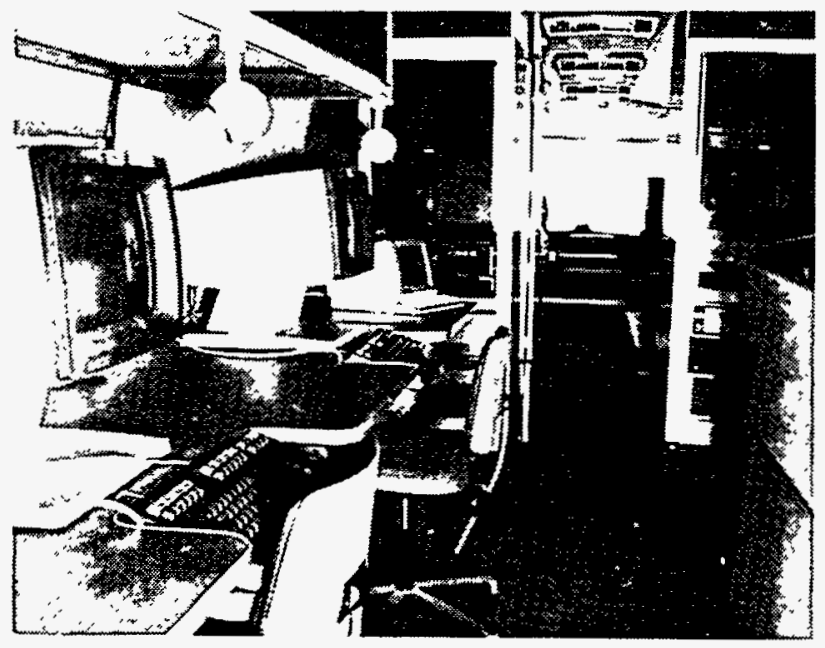

FIGURE 3. SURVEY DATA VAN

answered before committing a full complement of assets to the survey. Such questions as:

a. To what extent or distance is the fallout field measurable?

b. Will the GPS guidance system function adequately over long lines?

c. Will WSMR radar or other electromagnetic background impair gamma system operation?

A two-day effort was planned and executed.

4. Perform the survey with closely spaced lines in the GZ area, then broaden the line spacing as Cedarvale, New Mexico, was approached. North-south flight lines were planned, because the geologic upthrusts generally lie northsouth.

Flight safety was the first priority. Since the Trinity area is very rugged, altitudes of $91 \mathrm{~m}$ $(300 \mathrm{ft}$ ) above ground level (AGL) were judged safe as a minimum altitude only. Flights within and adjacent to the WSMR were under continuous range control.

5. Update data reduction on a flight-by-flight basis. No flight would be launched before the current gamma data were judged satisfactory.

6. Complete the basic fallout contour map before concluding the field work.

7. Coordinate ground measurement locations with the field technician. 5 
8. Conclude the aerial survey and return the data to the DOE Remote Sensing Laboratory for further analysis.

9. Organize the aerial and ground-based measurements and maps into a survey report.

\subsection{SURVEY CONDUCT}

A standardized procedure was followed during the Trinity survey. Steps in the procedure are:

1. A water line (Elephant Butte Reservoir) was flown with several passes each at a different altitude. Then passes at the same altitude AGL were made over a test line (a relocatable line near or in the survey area).

2. A perimeter flight of roads in the survey area was then made. The GPS data from this flight were used to scale distances to a road map of the survey area. In this way, each subsequent gamma datum could be plotted on the map. The GPS positions were purposely degraded to $\pm 100-200 \mathrm{~m}$ for nonmilitary use.

3. Following the perimeter and test line flights, routine survey flights began. All survey lines were flown at an altitude of $91 \mathrm{~m}$ (300 ft). Each flight, preceded by a preflight in which the system was calibrated and the data tape analyzed for proper system operation, consisted of:

a. A pass over the test line at survey altitude (91 $\mathrm{m} \mathrm{AGL}$ ) and again at $900 \mathrm{~m} \mathrm{AGL}$.

b. Passes in a north-south direction following preprogrammed adjacent lines over the survey area.

c. A repeat pass over the test line. Generally a water line is flown before or after the test lines, but Elephant Butte Reservoir was $70 \mathrm{~km}$ ( $43 \mathrm{mi}$ ) from GZ. Therefore, the reservoir was flown just three times during the survey.

4. Following each survey flight, the data were reduced to energy spectrum plots and parameter listings by a standard postflight computer program. These were examined by the survey scientist and data technician for integrity and quality. The reduced data were extrapolated to a common $91-m$ altitude above the ground and a contour map was drawn in count rate units.
A contour map also was drawn to show possible cesium-137( $\left.{ }^{137} \mathrm{Cs}\right)$ gamma activity.

Military activity at WSMR precluded a simple order of data acquisition. As an example, the first flight lines were flown in the Claunch, New Mexico, area rather than near $G Z$, because planned WSMR aerial traffic would have jeopardized the gamma survey and flight crew.

\subsection{DATA ANALYSIS}

The data analyst has these basic stored data acquired each second:

1. A 256-channel gamma energy spectrum, 20 $\mathrm{keV}$ to $4 \mathrm{MeV}$

2. Atmospheric temperature and pressure

3. Altitude above ground level (AGL)

4. Geographic position which at Trinity was provided by GPS (the satellite Global Positioning System)

These data are further grouped into sets:

1. Calibration data such as system response to known gamma point sources and to a known test line in Nevada

2. Preflight or system test data

3. Test line data near or in the survey area

4. Over-water data near the survey area

5. Primary flight line data over the survey area

6. Postflight system test data

7. The written flight log as recorded by the system operator

All of these data were used to provide a best estimate of the position, magnitude, and isotopic content in the Trinity survey area.

\subsection{Water Background and Test Lines}

Elephant Butte Reservoir was flown on three different days over the Trinity reservoir at five altitudes. One of the three test lines (near Tularosa, Carrizozo, and GZ) was flown on the same day either just before or after the water passes. Elephant Butte reservoir is 71 
$\mathrm{km}$ southwest of Trinity $\mathrm{GZ}$, so the number of water passes was limited.

The over-water data were subtracted directly from the test line data to yield net terrestrial spectra and count rates. Subsequent increases or decreases in test line count rate were then interpreted as increases or decreases in airborne radon. Adding or subtracting the change in test line count rates to the original water count rate yields an effective water count rate. Water count rates or effective water count rates from test lines were subtracted from the total gamma count rate to yield terrestrial count rates in the survey line data:

$$
G C=(T C-B) e^{\lambda(R A-91)}
$$

$$
\begin{aligned}
\text { where } & \\
G C & =\text { net gamma count rate at } 91 \mathrm{~m} \text { (cps) } \\
T C & =\text { total gamma count rate } \\
B & =\text { background (over-water count rate) } \\
\lambda & =\text { altitude coefficient, }(1 / \mathrm{m}) \\
R A & =\text { altitude above ground }(\mathrm{m})
\end{aligned}
$$

The altitude coefficient, $\lambda$, was determined as $0.00587 \mathrm{~m}^{-1}$ from $G C$ versus altitude measurements over the test lines. This value agrees with the value over the LMTL near Las Vegas, Nevada. Background values (or effective water count rates) for $G C$ averaged $2,500 \mathrm{cps}$ with a standard deviation of $300 \mathrm{cps}$ from the eighteen data flights at Trinity. Atmospheric radon variations, then, were normal (expected) and significant as compared to the normal terrestrial $G C$ at $5,500 \mathrm{cps}$.

\subsection{Gamma Energy Spectrum Stripping}

Early flight line data from the Trinity survey were examined for isotopic content. Survey test line spectra were subtracted from survey line spectra to yield net anomalous gamma photopeaks and consequently the source isotopes. Cesium-137 and europium-152 (152Eu) only were identified with this method.

Experience has shown that the photopeak stripping technique is the most sensitive for evaluating the magnitude of a particular gamma photopeak superimposed on background spectra (Appendix B). Two different window arrangements were used to extract the predominant ${ }^{137} \mathrm{Cs}$ gamma photopeak. These include a two-window and a three-window arrangement. The net ${ }^{137} \mathrm{Cs}$ photopeak count rate was extracted from each of the 53,000 survey energy spectra using the following equation:

$$
C s=(A-K B) e^{\lambda_{c}(R A-91)}
$$

$$
\begin{aligned}
& \text { where } \\
& C s=\text { net }{ }^{137} \mathrm{Cs} \text { photopeak count rate (cps) } \\
& A=\text { count rate in the photopeak window from } \\
& 554 \mathrm{keV} \text { to } 770 \mathrm{keV} \\
& K=\text { ratio of photopeak window }(A) \text { to back } \\
& \text { ground window }(B) \text { over a test line } \\
& B=\text { count rate in the background window from } \\
& 770 \mathrm{keV} \text { to } 1,370 \mathrm{keV} \\
& \lambda_{c}=\text { altitude coefficient }(1 / \mathrm{m}) \\
& R A=\text { radar altitude }(\mathrm{m})
\end{aligned}
$$

The ratio, $K$, was determined from test line spectra at a $91-\mathrm{m}$ altitude. The value of $K$ ranged from 0.74 on the test line near $G Z$ to 0.79 near Carrizozo. This coefficient was determined for each survey flight from test line data. The standard deviation for Cs, Equation 2 above, was about $30 \mathrm{cps}$.

The altitude coefficient, $\lambda_{c}$, was determined from the ${ }^{137} \mathrm{Cs}$ count rate versus altitude data over the cesium concentrations on Chupadera Mesa. The value was measured as $0.00935 \mathrm{~m}^{-1}$.

Europium-152, a neutron activation product in the soil, was also evaluated in a manner similar to that for ${ }^{137} \mathrm{Cs}$. A net spectrum was obtained and an extraction equation developed:

$$
E u=A-K B
$$

$$
\begin{aligned}
\text { where } & \\
E u= & \text { net }{ }^{152} \text { Eu count rate (cps) } \\
A= & \text { count rate in the signal window from } 854 \\
& \text { keV to } 1,592 \mathrm{keV} \\
B= & \text { count rate in the background window from } \\
& 1,592 \mathrm{keV} \text { to } 3,026 \mathrm{keV}
\end{aligned}
$$


The value of $K$ was 4.5 over the $\mathrm{GZ}$ test line and the standard deviation of ${ }^{152} \mathrm{Eu}$ was about $50 \mathrm{cps}$ on the same line. The altitude coefficient was not developed for this window arrangement because ${ }^{152} \mathrm{Eu}$ was found only in the immediate GZ area. ${ }^{2}$ The area west of the Oscura mountains was searched, however, for any other evidence of ${ }^{152} \mathrm{Eu}$ using both Equation 3 and net spectra.

Considerable effort was directed in a search for americium-241 ( $\left.{ }^{241} \mathrm{Am}\right)$, generally associated with plutonium-239 (239Pu), the Trinity fissile material. None was detected either with the photopeak (at $60 \mathrm{keV}$ ) spectral equation or with the net spectrum technique. Most of the data were examined with the following equation:

$$
A m=(A-K B) e^{\lambda(R A-91)}
$$

where

$$
\begin{aligned}
& A m=\text { net }{ }^{241} \mathrm{Am} \text { photopeak count rate at } 91 \mathrm{~m} \\
& \text { (cps) } \\
& A=\text { count rate in the photopeak window from } \\
& 50 \mathrm{keV} \text { to } 70 \mathrm{keV} \\
& K=\text { ratio of } A \text { to } B \text { over a test line } \\
& B=\text { count rate in the background windows } \\
& \text { from } 38 \mathrm{keV} \text { to } 50 \mathrm{keV} \text { and } \\
& \text { from } 70 \mathrm{keV} \text { to } 82 \mathrm{keV} \\
& \lambda=\text { altitude coefficient }(1 / \mathrm{m}) \\
& R A=\text { radar altitude }(\mathrm{m})
\end{aligned}
$$

The value of $K$ was about 1.00 and the standard deviation of $A m$ about $30 \mathrm{cps}$ from test line data at a $91-\mathrm{m}$ altitude.

\subsection{Counting Statistics and Detection Limit}

The primary counting statistics resulting from limited count rates, varying natural isotope concentrations, and ground roughness were computed from test line data in the following manner:

$$
\sigma(C R)=\left[\sum_{1}^{N} \frac{\left(C R-C R_{a}\right)^{2}}{N-1}\right]^{1 / 2}
$$

where

$$
\begin{aligned}
\sigma(C R)= & \begin{array}{l}
\text { standard deviation of the count rate of } \\
\text { interest, } C R
\end{array} \\
C R_{a}= & \begin{array}{l}
\text { average count rate over the test line } \\
\text { (cps) }
\end{array} \\
N= & \text { the number of data points along the } \\
& \text { test line (of order } 100)
\end{aligned}
$$

The standard deviation was also evaluated over survey flight lines or portions of flight lines where anomalous isotopes are absent.

The detection limit was set at three times the standard deviation, $3 \sigma(C R)$, of the count rate of interest. This limit is called the critical level by Curie. ${ }^{6}$ All count rates above $3 \sigma$ were included in the contour maps of specific isotopes such as the ${ }^{137} \mathrm{Cs}$ map of Trinity fallout. The expected rate of false alarms, then, is less than one percent, and the expected signal loss rate is $50 \%$ at $3 \sigma$.

From 21 to 84 data points (dependent on actual line separation) were averaged or accumulated to produce the Trinity ${ }^{137} \mathrm{Cs}$ contour map. This averaging of the data points reduces the $3 \sigma$ minimum contour by the square root of the number of averaged data points, but produces a loss in spatial resolution.

Data averaging was generally carried out over square areas from $2,500 \mathrm{ft}(762 \mathrm{~m})$ on a side to $10,000 \mathrm{ft}$ $(3,000 \mathrm{~m})$ on a side. The ${ }^{137} \mathrm{Cs}$ map chosen for publication was averaged over areas $5,000 \mathrm{ft}(1,500 \mathrm{~m})$ on a side or about $0.9 \mathrm{mi}^{2}\left(2.3 \mathrm{~km}^{2}\right)$.

\subsection{Map Verification with Energy Spectra}

The ${ }^{137} \mathrm{Cs}$ contours may include false contours at low levels originating from the $609-\mathrm{keV}$ bismuth-214 (214 $\mathrm{Bi})$ photopeak. Bismuth-214 is a uranium-238 $\left.{ }^{238} \mathrm{U}\right)$ daughter and is a naturally-occurring radionuclide. Net spectra were derived over most contoured areas in a search for false contours. Net spectra are obtained by subtracting a background spectrum from the total spectrum of a given area. If the ${ }^{137} \mathrm{Cs}$ photopeak is not evident, or the ${ }^{214} \mathrm{Bi}$ photopeak is the overwhelming predominant peak in the signal window, then the area is deleted from the map. The ${ }^{137} \mathrm{Cs}$ photopeak (in net spectra) was clearly visible at the minimum contour level (15 cps). 


\subsection{Exposure and Isotope Concentration Estimates}

The gamma exposure rate at $1 \mathrm{~m}$ AGL was interpreted from the $G C$ (Equation 1) at the 91 -m altitude. The conversion of count rate to $\mu \mathrm{R} / \mathrm{h}$ was determined from the LMTL. The terrestrial exposure at $1 \mathrm{~m} \mathrm{AGL}$ for the LMTL has previously been measured by several experimenters. The aerial gamma system was operated at several altitudes over the LMTL and the $G C$ obtained at each altitude. The flight lines included the adjacent water in Lake Mead, so background and over-water count rates were available. Both the count rate versus altitude and the count rate per unit exposure rate were obtained.

$$
R=\frac{10.4 e^{0.00587 A}}{16152}=0.0011
$$

where

$$
\begin{aligned}
R= & \text { exposure rate }(\mu \mathrm{R} / \mathrm{h} / \mathrm{cps}) \\
\text { coefficient } 10.4= & \text { exposure rate over LMTL at } \\
& 1 \mathrm{~m} \mathrm{AGL} \\
A= & \text { altitude, } 91 \mathrm{~m} \\
\text { coefficient } 16152= & \text { count rate over LMTLat } 1 \mathrm{~m} \\
& \mathrm{AGL}
\end{aligned}
$$

This experiment was repeated over the Trinity test line and yielded the same altitude coefficient, but ground level exposure rate measurements were not obtained on the Trinity test line.

Cesium-137 concentration estimates in the soil were computed from the ${ }^{137} \mathrm{Cs}$ count rates (Equation 2). The basic computation is outlined in Appendix $B$. The result is:

$$
\text { cesium concentration }=0.0019 \mu \mathrm{Ci} / \mathrm{m}^{2} / \mathrm{cps}
$$

where the vertical concentration distribution, $S$, is described by:

$$
S=S_{0} e^{-0.2 D}
$$

where

$$
D=\text { depth is soil (cm) }
$$

Finally, estimates were made of the exposure rate due to cosmic rays in the Trinity area:

$$
C=2.7735 e^{0.0004523 A}+0.81305 e^{-0.0008 A}
$$

where

$$
\begin{aligned}
& C=\text { cosmic exposure rate }(\mu R / h) \\
& A=\text { altitude }(\mathrm{m})
\end{aligned}
$$

The cosmic exposure equation is a fit to data reported by DOE's Environmental Measurement Laboratory in New York City.

\subsection{RESULTS}

The principal results of the Trinity aerial gamma survey are the contour maps that show the location and relative concentration of isotopes that comprise the Trinity fallout field. The only fallout isotope detectable was ${ }^{137} \mathrm{Cs}$, a fission product. Other fallout isotopes have decayed to concentrations less than the limit of detection of the aerial system.

A large concentration of ${ }^{152} \mathrm{Eu}$, from neutron activation in the soil, was found at GZ but not downwind in the fallout field.

Ground-based measurements of exposure and soil isotope concentrations are compared with exposure and concentration estimates from the aerial data.

\subsection{Cesium Contour Map}

\subsubsection{General Characteristics}

The ${ }^{137} \mathrm{Cs}$ contour map (Figure 4) defines most of the Trinity fallout field detectable by the aerial system. The map has been produced from ${ }^{137} \mathrm{Cs}$ count rates originating in the $\mathrm{Nal}(\mathrm{Tl})$ aerial detector package. Data points have been averaged in 5,000-ft blocks over the survey area. One point per block has been used to produce the contour map. The averaging process reduces the complexity and spatial resolution of the map but allows a lower minimum detection limit 


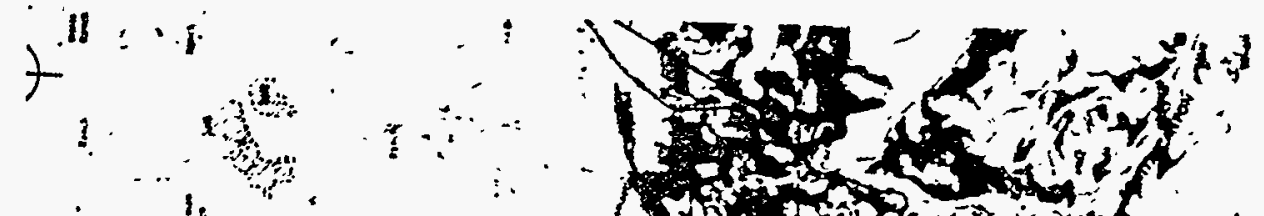

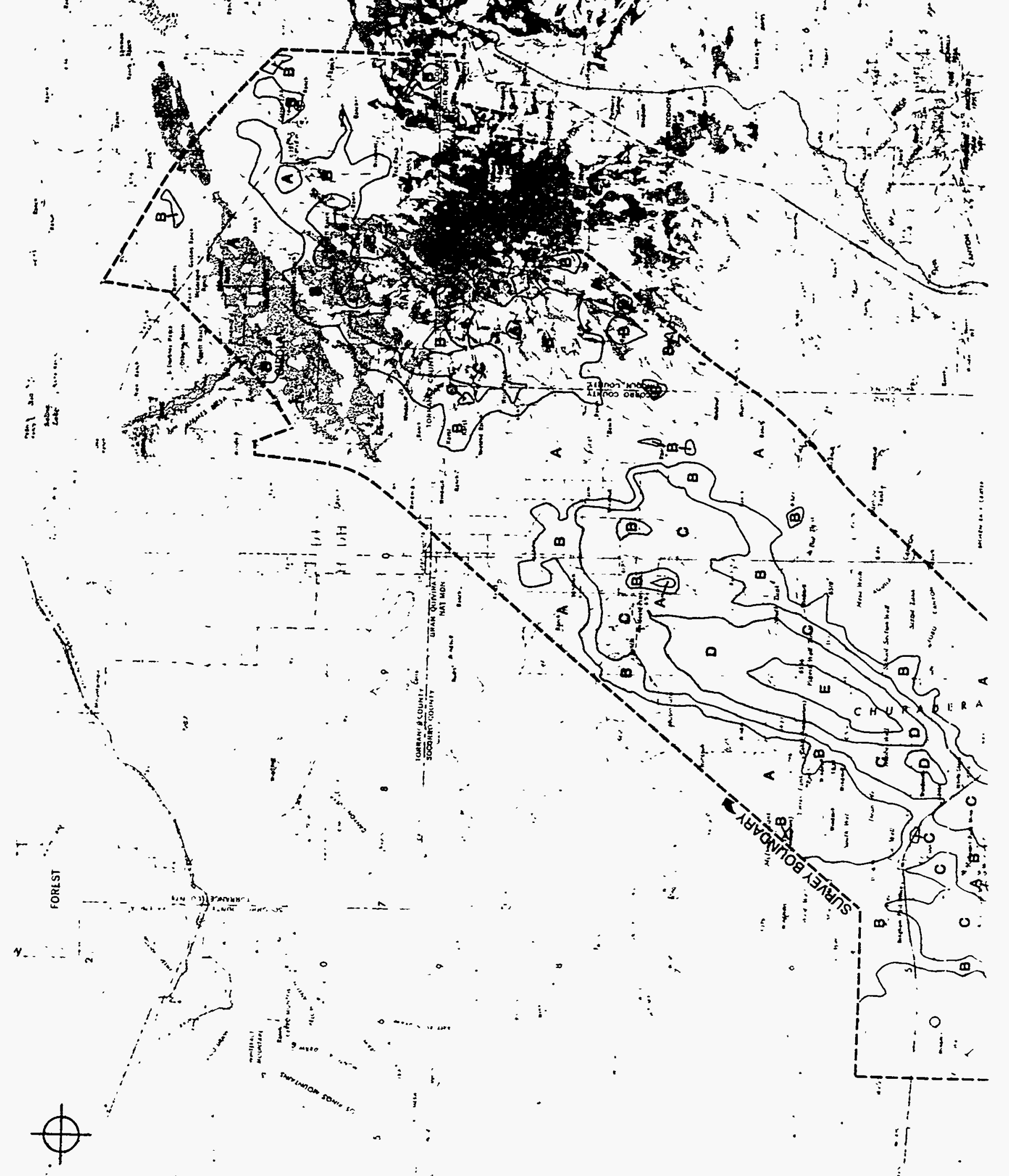


versus nonaveraged data. Other maps with minimum averaging have been produced and are available.

The basic minimum detection limit has been set at $3 \sigma$ (three standard deviations) of the background count rate algorithm. The detection limit is about $90 \mathrm{cps}$ for the ${ }^{137} \mathrm{Cs}$ detection algorithm. The detection limit (the lowest contour) has been lowered by the factor $1 / \sqrt{N}$ for $N$ averaged points. The number of averaged points varies from 21 near Cedarvale, to 42 on Chupadera Mesa, and to 84 in the GZ area. The lowest contour at $15 \mathrm{cps}$ approximates the detection limit over Chupadera Mesa.

Contour levels range from $15 \mathrm{cps}$ to $120 \mathrm{cps}$ as measured from the ${ }^{137} \mathrm{Cs}$ photopeak. Maxima occur near $\mathrm{GZ}$ at $270 \mathrm{cps}$ (located $1 \mathrm{~km}$ from GZ and angle $7^{\circ}$ east of north), and at $216 \mathrm{cps}\left(33 \mathrm{~km}, 42.6^{\circ}\right)$ on Chupadera Mesa. These are maxima of individual 1 -second measurements, while Figure 4 includes the averaging effects discussed above. The total gamma energy spectrum and the ${ }^{137} \mathrm{Cs}$ spectrum obtained over Chupadera Mesa are shown in Figures 5 and 6.

The character of the cesium contours suggests a major fallout field extending from the $G Z$ to beyond Cedarvale (105 km, 37 from GZ) and another fallout field extending to Bingham $\left(30 \mathrm{~km}, 18^{\circ}\right)$. These are consistent with cloud observations at zero hour in 1945. ${ }^{1}$

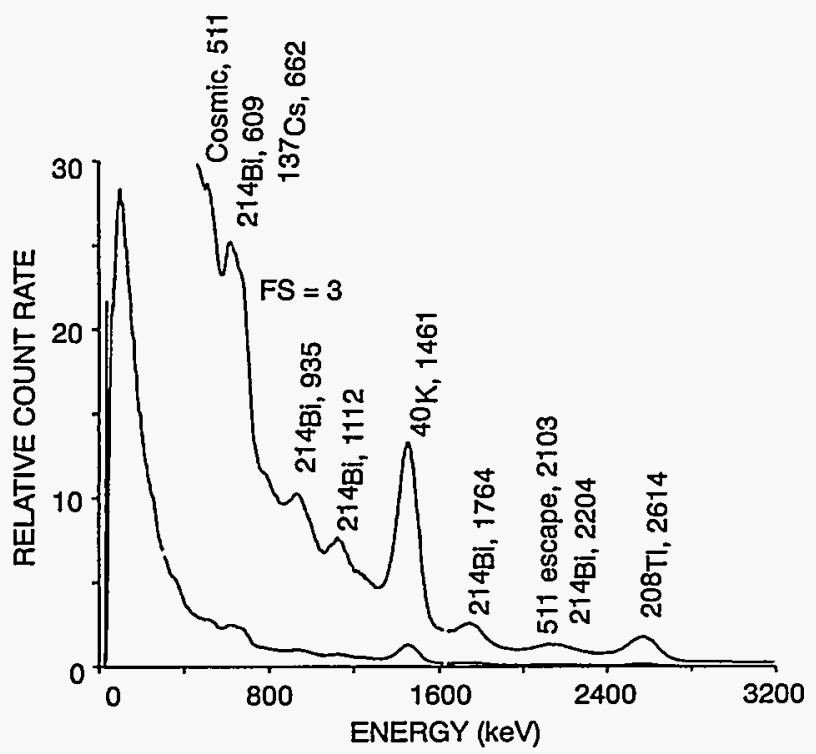

FIGURE 5. TOTAL GAMMA ENERGY SPECTRUM OVER CHUPADERA MESA
The area bounded by the lowest contour level is close to $1,400 \mathrm{~km}^{2}$. More coverage details are discussed in the following section.

\subsubsection{Cesium Concentration}

Estimates of ${ }^{137} \mathrm{Cs}$ concentrations in the soil may be computed from aerial data (Appendix $B$ ) if the vertical distribution of ${ }^{137} \mathrm{Cs}$ is known in this form:

$$
C=C_{o} e^{-a z}
$$

where

$$
\begin{aligned}
C= & \text { the }{ }^{137} \mathrm{Cs} \text { concentration in the ground } \\
& \left(\frac{p C i}{c m^{3}}\right) \\
C_{0}= & \text { the }{ }^{137} \mathrm{Cs} \text { concentration at the surface } \\
& \left(\frac{p C i}{\mathrm{~cm}^{3}}\right) \\
\alpha= & \text { distribution parameter }(1 / \mathrm{cm}) \\
z= & \text { depth in soil }(\mathrm{cm})
\end{aligned}
$$

Reference 2 suggests a reasonable value is $\alpha=0.2$ $\mathrm{cm}^{-1}$. Since $\alpha$ is not well known and is variable, ${ }^{2}$ aerial estimates of ${ }^{137} \mathrm{Cs}$ concentration are necessarily uncertain. Some useful photopeak count rate to ${ }^{137} \mathrm{Cs}$ concentration conversion values are listed in Table 1.

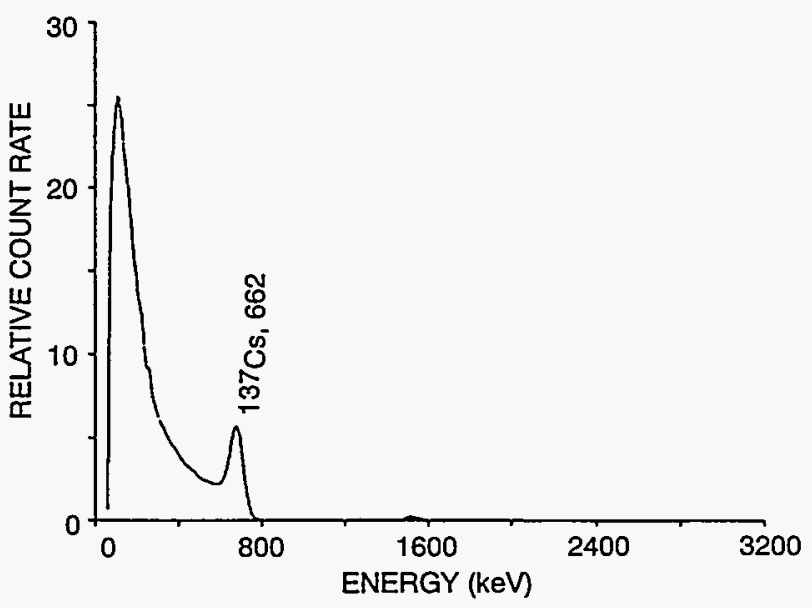

FIGURE 6. CESIUM-137 GAMMA ENERGY SPECTRUM OVER CHUPADERA MESA 
Table 1. Aerial Count Rate Conversions to Cesium-137 Concentration and to Exposure Rate

\begin{tabular}{|c|c|c|c|c|}
\hline $\begin{array}{c}\alpha \\
(\mathbf{c m} \\
-1\end{array}$ & $\begin{array}{c}\text { Area } \\
\text { Concentration } \\
{ }^{2}\left(\mu \mathrm{Ci} / \mathrm{m}^{2} / \mathrm{cps}\right)\end{array}$ & $\begin{array}{c}\text { Mass } \\
\text { (surface) } \\
\text { Concentration } \\
\text { a (pCi/g/cps) }\end{array}$ & $\begin{array}{c}\text { Mass (15-cm } \\
\text { sample) } \\
\text { Concentration } \\
\text { a (pCi/g/cps) }\end{array}$ & $\begin{array}{c}\text { Exposure } \\
\text { Rate at 1m } \\
\text { AGL } b^{b} \\
(\mu \mathrm{R} / \mathrm{h} / \mathrm{cps})\end{array}$ \\
\hline .2 & 0.0019 & 0.0242 & 0.0096 & 0.0068 \\
.1 & 0.0028 & 0.0181 & 0.010 & 0.0067 \\
.05 & 0.0045 & 0.0149 & 0.011 & 0.0067 \\
.01 & 0.0183 & 0.0122 & 0.011 & 0.0068 \\
\hline
\end{tabular}

a The concentration estimate is derived from both measurement and computation (see Appendix $B$ ).

b Exposure rates are derived from the concentration estimates combined with the work of Beck,

DeCampo, and Gogolak (Reference 7).

Expected ${ }^{137} \mathrm{Cs}$ concentrations and external gamma exposure levels may be computed using values from Table 1 and an $\alpha$ value of $0.2 \mathrm{~cm}^{-1}$.

1. The maximum ${ }^{137} \mathrm{Cs}$ concentration and external exposure rate near $\mathrm{GZ}$ at $270 \mathrm{cps}$ are 0.5 $\mu \mathrm{Ci} / \mathrm{m}^{2}$ and $1.8 \mu \mathrm{R} / \mathrm{h}$, respectively.

2. The maximum values on Chupadera Mesa at $216 \mathrm{cps}$ are $0.41 \mu \mathrm{Ci} / \mathrm{m}^{2}$ and $1.5 \mu \mathrm{R} / \mathrm{h}$.

3. At the detection limit, $15 \mathrm{cps}$, concentration and external exposure are $0.03 \mu \mathrm{Ci} / \mathrm{m}^{2}$ or 0.36 $\mathrm{pCi} / \mathrm{g}$ at the surface and $0.10 \mu \mathrm{R} / \mathrm{h}$.

\subsubsection{Cesium Inventory}

The total quantity or inventory of ${ }^{137} \mathrm{Cs}$ activity detectable by the aerial system may be evaluated from the data used to construct the map in Figure 4. The inventory is simply the sum of the product of the mean concentration in each block and the area of the block, where each block of data measured $5,000 \mathrm{ft}$ or 1,524 $m$ on a side. Table 2 lists the inventory of geographic sections of the fallout pattern as well as the totals.

\subsection{Aerial and Ground-Based Exposure Measurements}

\subsubsection{Exposure Rate Map}

The gamma exposure rate at $1 \mathrm{~m}$ AGL may be computed from the aerial total count rate data $(G C$ in
Appendix B). An exposure contour map, Figure 7, at $3 \mu \mathrm{R} / \mathrm{h}$ intervals shows the terrestrial exposure rate over the survey area. A smaller interval between contours yields a complex map that is difficult to read. More details are available, however, in a larger format.

Terrestrial exposure is due primarily to the natural gamma emitters in the soil (thorium-232 [ $\left.{ }^{232} \mathrm{Th}\right]$ and daughters, ${ }^{238} \mathrm{U}$ and daughters, and potassium-40 $\left[{ }^{40} \mathrm{~K}\right]$ ). Note that the significant cosmic contribution (6 $\mu \mathrm{R} / \mathrm{h}$ or more) is not included in the map.

The terrestrial exposure rate distributions show that much of the survey area is at about $4.4 \mu \mathrm{R} / \mathrm{h}$ with a few exceptions. The most probable exposure west of $\mathrm{GZ}$ is $4.4 \mu \mathrm{R} / \mathrm{h}$. Between $\mathrm{GZ}$ and the Oscura Mountains, two distinct exposure rates exist at $4.4 \mu \mathrm{R} / \mathrm{h}$ and $9.9 \mu \mathrm{R} / \mathrm{h}$. Apparently, alluvium at exposures above 15 $\mu R / h$ from the Oscura escarpment extends toward the GZ. These are visible at the base of the Oscura Mountains on the map. From the Oscura Mountains to the Chupadera Mesa $4.4 \mu \mathrm{R} / \mathrm{h}$ is most probable, while the Chupadera Mesa itself is at $4.7 \mu \mathrm{R} / \mathrm{h}$. In the Claunch area, the exposure rises to $6.8 \mu \mathrm{R} / \mathrm{h}$. There is a small area about $5 \mathrm{~km}$ WSW of Gallinas Peak that approaches $21 \mu \mathrm{R} / \mathrm{h}$. Energy spectra show enhanced thallium-208, a daughter of ${ }^{232} \mathrm{Th}$.

\subsubsection{Ground-Based Exposure and Concentration Results}

Ground-based ion chamber measurements and soil samples were gathered during the aerial survey. ${ }^{8}$ 


\begin{tabular}{|c|c|c|c|}
\hline \multicolumn{2}{|r|}{ Section $^{a}$} & $\begin{array}{l}\text { Inventoryb } \\
\text { (Ci) }\end{array}$ & $\begin{array}{l}\text { Active Area } \\
\left(\mathbf{k m}^{2}\right)\end{array}$ \\
\hline A. & $\begin{array}{l}\mathrm{GZ} \text {, Jornado Del Muerto }(1.5 \mathrm{~km} \\
\text { west to } 6.7 \mathrm{~km} \text { east) }\end{array}$ & 12.3 & 133 \\
\hline B. & $\begin{array}{l}\text { Oscura Mts. ( } 6.7 \mathrm{~km} \text { east to } 10.0 \\
\mathrm{~km} \text { east) }\end{array}$ & 3.9 & 69 \\
\hline & $\begin{array}{l}\text { Oscura Mts. to Chupadera Mesa } \\
(10 \mathrm{~km} \text { east to } 20 \mathrm{~km} \text { east) }\end{array}$ & 13.8 & 242 \\
\hline & $\begin{array}{l}\text { Chupadera Mesa ( } 20 \mathrm{~km} \text { east to } \\
33 \mathrm{~km} \text { east) }\end{array}$ & 37.4 & 324 \\
\hline & $\begin{array}{l}\text { Claunch, NM and Gallinas Peak } \\
\text { ( } 33 \mathrm{~km} \text { east to } 73 \mathrm{~km} \text { east) }\end{array}$ & 32.4 & 628 \\
\hline & Total & 99.8 & 1,396 \\
\hline
\end{tabular}

The reference point is $G Z$ for all sections. Distances are given in the west to east direction.

${ }^{b}$ The ${ }^{137}$ Cs vertical concentration has been assumed as $C=C_{o} \exp (-0.2 Z)$. See Equation 9 .

Sample locations are shown on the exposure map (Figure 7). The aerial exposure rates are compared to the ion chamber measurement and to the computed exposure from soil sample results in Table $3 .^{9}$ The agreement appears quite close, though the aerial system evaluates as much as one-third of a square kilometer while the ion chamber and soil samples evaluate a much smaller area.

Soil moisture, and the concentrations of ${ }^{238} \mathrm{U}$ and (radon-226), ${ }^{232} \mathrm{Th}$, and ${ }^{40} \mathrm{~K}$ from soil sample measurements are given in Table 4. These agree within $10 \%$ of the natural isotope concentrations in the LMTL soil. Therefore, exposure rate conversion factors, derived from LMTL, should be applicable in the Trinity area.

A comparison of ${ }^{137} \mathrm{Cs}$ concentrations obtained from both soil samples and aerial data is given in Table 5 . Only four of the aerial data locations were above the aerial detection limit, though the soil sample concentrations suggest that ten should have been. Note that five soil sample concentration values are just above the aerial detection limit of $0.15 \mathrm{pCi} / \mathrm{g}$ (average concentration in the top $15 \mathrm{~cm}$ of soil).

\subsubsection{Cesium-137 Exposure Rates}

Cesium-137 from international fallout contributes a very small exposure, perhaps $0.1 \mu R / h$ for the little remaining international fallout. ${ }^{3}$ The Trinity fallout, however, may contribute as much as $1.8 \mu \mathrm{R} / \mathrm{h}$ near $\mathrm{GZ}$, and $1.5 \mu \mathrm{R} / \mathrm{h}$ on Chupadera Mesa. These fallout exposure rates do not appear clearly on the exposure rate map, perhaps because the geology is so variable.

\subsubsection{Europium-152 Exposure Rate}

Neutron activation in the soil during the Trinity event created significant ${ }^{152} \mathrm{Eu}$ at ground zero. The exposure rate from the many ${ }^{152}$ Eu gammas is the largest measured by the aerial system in the survey area. The maximum $1-\mathrm{m}$ exposure rate is estimated at 70 $\mu R / h$ and is confined to a $500-m$ radius from $G Z$, as detected by the aerial system. The ${ }^{152} \mathrm{Eu}$ gamma energy spectrum as recorded at the $91-\mathrm{m}(300-\mathrm{ft})$ altitude is shown in Figure 8.

\subsection{DISCUSSION}

The geographic coverage of the Trinity fallout field has been defined here by the fission product ${ }^{137} \mathrm{Cs}$. 


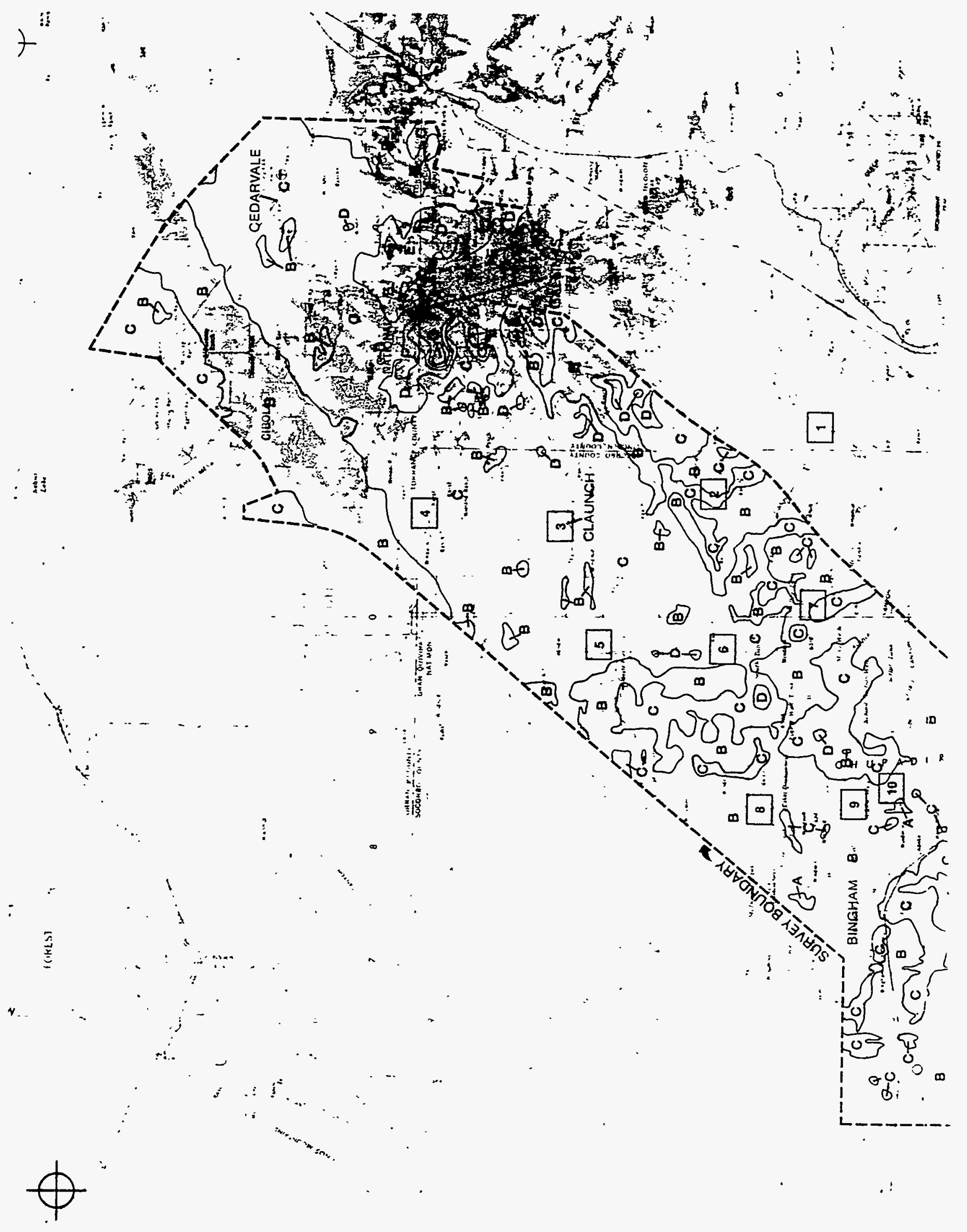




\begin{tabular}{|c|c|c|c|}
\hline \multicolumn{4}{|c|}{ Table 3. Trinity Area Gamma Exposure Rates } \\
\hline \multirow{2}{*}{ Location } & $\begin{array}{c}\text { Soil Sample } \\
(\mu \mathrm{R} / \mathrm{h})\end{array}$ & $\begin{array}{c}\text { lon Chamber } \\
(\mu \mathrm{R} / \mathrm{h})\end{array}$ & $\begin{array}{c}\text { Aerial }^{\mathrm{b}} \\
(\mu \mathrm{R} / \mathrm{h})\end{array}$ \\
\hline 1 & $12.5 \pm 0.7$ & $14.2 \pm 0.7$ & 12.8 \\
2 & $10.0 \pm 3.0$ & $11.1 \pm 0.6$ & 12.0 \\
3 & $12.8 \pm 0.8$ & $11.9 \pm 0.6$ & 14.2 \\
4 & $14.0 \pm 2.0$ & $14.9 \pm 0.7$ & 13.0 \\
5 & $14.5 \pm 0.9$ & $15.6 \pm 0.8$ & 14.3 \\
6 & $14.4 \pm 0.7$ & $14.0 \pm 0.7$ & 15.1 \\
7 & $13.2 \pm 0.7$ & $13.2 \pm 0.7$ & 11.1 \\
8 & $12.4 \pm 1.0$ & $13.0 \pm 0.7$ & 13.7 \\
9 & $10.3 \pm 0.8$ & $11.4 \pm 0.6$ & 10.9 \\
10 & $11.2 \pm 1.2$ & $12.4 \pm 0.6$ & 12.6 \\
11 & $13.4 \pm 0.8$ & $13.4 \pm 0.7$ & 10.0 \\
Average & $12.6 \pm 1.5$ & $13.1 \pm 1.4$ & $12.7 \pm 1.6$ \\
\hline
\end{tabular}

a Soil sample and ion chamber uncertainties are at one standard deviation.

b The aerial exposure uncertainty is about $1 \mu \mathrm{P} / \mathrm{h}$.

Table 4. Isotope Concentrations and Soil Moisture Obtained from Soil Samples Average Isotope Concentration ${ }^{\mathrm{a}}$ in $\mathrm{pCi} / \mathrm{g} \pm \mathrm{SD}$

\begin{tabular}{|c|c|l|l|l|l|}
\hline Location & \% Moisture & \multicolumn{1}{|c|}{${ }^{226} \mathrm{Ra}$} & \multicolumn{1}{|c|}{${ }^{232} \mathrm{Th}$} & $137 \mathrm{Cs}$ & ${ }^{40 \mathrm{~K}}$ \\
\hline 1 & $10 \pm 1$ & $0.8 \pm 0.1$ & $0.88 \pm 0.06$ & $0.08 \pm 0.05$ & $14.6 \pm 0.4$ \\
2 & $14 \pm 2$ & $0.5 \pm 0.3$ & $0.5 \pm 0.3$ & $0.18 \pm 0.09$ & $10 \pm 5$ \\
3 & $6.8 \pm 0.7$ & $0.69 \pm 0.03$ & $0.78 \pm 0.09$ & $0.2 \pm 0.2$ & $15 \pm 2$ \\
4 & $7 \pm 2$ & $0.7 \pm 0.2$ & $0.9 \pm 0.2$ & $1.1 \pm 0.3$ & $18 \pm 2$ \\
5 & $10 \pm 1$ & $0.89 \pm 0.06$ & $1.1 \pm 0.1$ & $0.8 \pm 0.4$ & $19 \pm 1$ \\
6 & $10.9 \pm 0.8$ & $1.1 \pm 0.2$ & $0.99 \pm 0.04$ & $0.2 \pm 0.1$ & $17.8 \pm 0.7$ \\
7 & $12.2 \pm 0.7$ & $0.75 \pm 0.03$ & $0.93 \pm 0.02$ & $0.2 \pm 0.1$ & $18.1 \pm 0.5$ \\
8 & $13 \pm 3$ & $0.75 \pm 0.07$ & $0.8 \pm 0.1$ & $0.17 \pm 0.06$ & $15 \pm 2$ \\
9 & $10 \pm 1$ & $0.7 \pm 0.1$ & $0.45 \pm 0.05$ & $0.7 \pm 0.4$ & $7.5 \pm 0.5$ \\
10 & $9 \pm 1$ & $0.5 \pm 0.1$ & $0.40 \pm 0.04$ & $0.6 \pm 0.4$ & $14 \pm 2$ \\
11 & $14 \pm 2$ & $0.93 \pm 0.07$ & $0.93 \pm 0.08$ & $0.3 \pm 0.3$ & $17.6 \pm 0.9$ \\
\hline
\end{tabular}

a Uncertainties represent one standard deviation. 


\begin{tabular}{|c|c|c|}
\hline \multicolumn{2}{|c|}{ Table 5. $\begin{array}{c}\text { Aerial/Soil Sample Cesium-137 Concentration } \\
\text { Comparison }\end{array}$} \\
\hline $\begin{array}{c}\text { Soil Sample } \\
\text { Location }{ }^{\mathrm{a}}\end{array}$ & $\begin{array}{c}\text { Soil Sample }{ }^{137} \mathrm{Cs} \\
\text { Concentrations } \\
\text { (pCi/g) }\end{array}$ & $\begin{array}{c}\text { Aerial }{ }^{137} \text { Cs } \\
\text { Concentration } \\
\text { (pCi/g) }\end{array}$ \\
\hline 1 & $0.08 \pm 0.05$ & $\mathrm{~d}$ \\
2 & $0.18 \pm 0.09$ & $<0.15$ \\
3 & $0.20 \pm 0.20$ & $<0.15$ \\
4 & $1.10 \pm 0.30$ & $<0.15$ \\
5 & $0.80 \pm 0.40$ & 0.30 \\
6 & $0.20 \pm 0.10$ & 0.30 \\
7 & $0.20 \pm 0.10$ & $<0.15$ \\
8 & $0.17 \pm 0.06$ & $<0.15$ \\
9 & $0.70 \pm 0.40$ & 0.60 \\
10 & $0.60 \pm 0.40$ & 1.20 \\
11 & $0.30 \pm 0.30$ & $<0.15$ \\
\hline
\end{tabular}

a Locations are shown on the Exposure Rate map, Figure 7.

bSoil sample ${ }^{137} \mathrm{Cs}$ concentration uncertainties are given at one standard deviation.

c Cesium-137 concentration uncertainties from aerial data are not known for concentrations less than $0.15 \mathrm{pCi} / \mathrm{g}$. Uncertainties are expected within a factor of two for concentrations larger than $0.15 \mathrm{pCi} / \mathrm{g}$.

dNo aerial data at this location.

Further, the lowest level at the edge of the fallout field, $0.15 \mathrm{pCi} / \mathrm{g}$, (average in top $15 \mathrm{~cm}$ of soil) is consistent with the level of international fallout in New Mexico, 0.1 to $1.0 \mathrm{pCi} / \mathrm{g} .^{2}$ No other man-made isotopes were visible or measurable in or near the fallout field other than at GZ. Ground zero contains appreciable ${ }^{152} \mathrm{Eu}$. The ${ }^{137} \mathrm{Cs}$ contour map, then, is expected to represent the location and relative concentrations of much of the Trinity fallout, whether measurable or not.

The data points used to describe the cesium map have been averaged heavily such that the original 53,000 data points have been reduced to about 1,500. The advantage is a lower detection limit. The disadvantage is a loss of geographic resolution to about $1 \mathrm{~km}$. The low detection limit does show the northerly Trinity fallout plume extending to the survey boundary, near Bingham, New Mexico. The flight lines in this area of the survey should have been longer in order to map all of the measurable fallout (cesium-137).

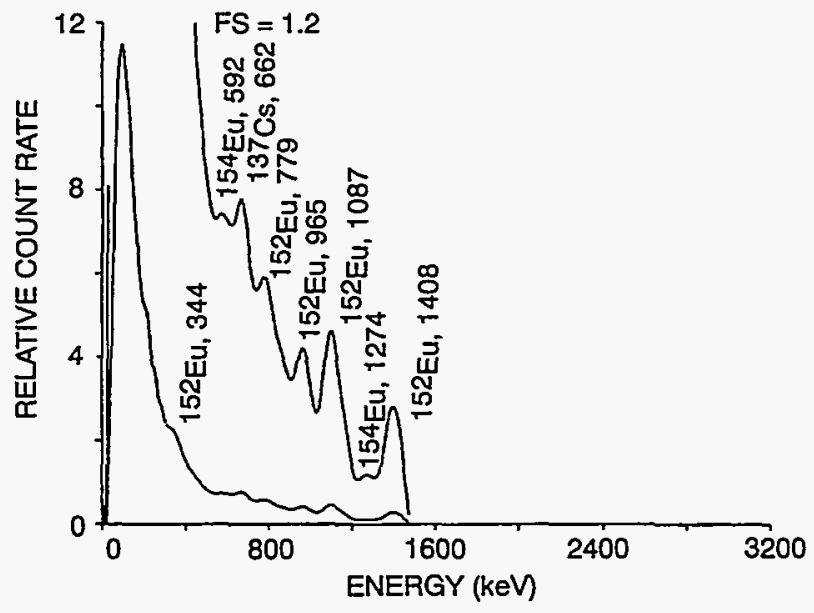

FIGURE 8. TERRESTRIAL GAMMA ENERGY SPECTRUM OVER TRINITY GROUND ZERO

Perhaps the most difficult technical problem in the aerial Trinity survey is the interpretation of the data over the Oscura Mountains and Gallinas Peak where survey altitude variations of $300 \mathrm{~m}$ or more occur. The 
${ }^{137} \mathrm{Cs}$ survey count rates decrease by one-half for each $80-\mathrm{m}$ increase in altitude, so that a substantial concentration is no longer measurable at the higher altitudes. There is ${ }^{137} \mathrm{Cs}$ on the Oscura Mountains, as analysis of gamma energy spectra indicate. But, the quantity is uncertain, because the aerial system is calibrated only for flat terrain.

The surface exposure rates at $1 \mathrm{~m}$ AGL on the Oscura escarpment are also suspect, because of the non- standard measurement geometry. The exposure rate map shows very large exposure rate changes on the face of the escarpment. Certainly there are some highly radioactive, natural rock types in the layers exposed by the fault line of the escarpment. This material appears to have weathered and washed or fallen down the slopes leading to the escarpment. In support of the aerial measurement, though, the soil sample and ion chamber results agree with the aerial measurement over a large area. 


\section{APPENDIX A}

\section{SURVEY PARAMETERS}

\section{Survey Dates}

Presurvey:

May 6 and 7, 1992

Survey:

May 11 through June 2, 1992

Hardware

Aircraft:

Beechcraft A-100 fixed-wing

Detectors:

Eight 4- $\times 4-\times 16$-in $\mathrm{Nal}(\mathrm{T} l)$

Data Acquisition System:

REDAR IV

Steering:

GPS

Data Van:

Data General MV7800XP Computer

\section{Area Coverage}

Area:

$3,150 \mathrm{~km}^{2}\left(1,216 \mathrm{mi}^{2}\right)$

Number of Flight lines:

115

Average Line Length:

$37 \mathrm{~km}$ (23 mi)

Flight Line Spacing:

Line Direction:

Variable: $381 \mathrm{~m}, 762 \mathrm{~m}$, and 1,524 m

North/South

\section{Data}

Acquisition Rate:

Once per second

Data Type:

Gamma energy spectra, atmospheric pressure and temperature, radar altitude above ground, geographic position

Flight Altitude:

$91 \mathrm{~m}(300 \mathrm{ft})$

\section{Results}

Isotopes Detected:

Primarily ${ }^{137} \mathrm{Cs},{ }^{152} \mathrm{Eu}$, and ${ }^{154} \mathrm{Eu}$

Deposition Extent:

Ground Zero, WSMR, NM to Cedarvale, NM (0-100 km)

Area of Deposition: $1,400 \mathrm{~km}^{2}$ (500 $\mathrm{mi}^{2}$ ) (as measured)

Quantity of Deposition:

$100 \mathrm{Ci}$ of ${ }^{137} \mathrm{Cs}$ (as measured) 


\section{APPENDIX B}

\section{GENERAL DATA ANALYSIS METHODS}

A few useful methods to treat gamma energy spectra as measured by $\mathrm{Nal}(\mathrm{T} l)$ are discussed below.

\section{B.1 GROSS COUNT RATE}

The gross count $(G C)$ rate is defined as the integral count in the energy spectrum (ES) between $38 \mathrm{keV}$ and $3,026 \mathrm{keV}$.

$$
G C=\sum_{E=38 \mathrm{keV}}^{3026 \mathrm{keV}} E S
$$

This sum includes all the natural isotope gammas from ${ }^{40} \mathrm{~K},{ }^{238} \mathrm{U}$, and ${ }^{232} \mathrm{Th}$ (KUT, the major terrestrial, natural gamma emitters). Other natural contributors are cosmic rays, aircraft background, and airborne radon daughters.

The response versus altitude of the aerial system to terrestrial gammas has been measured over a documented test line near Las Vegas, Nevada, for which the concentrations of KUT and the 1-meter exposure rates have been measured separately. From this calibration, the terrestrial gross count rate has been associated with the 1-meter exposure rate in microroentgens per hour $(\mu \mathrm{R} / \mathrm{h})$ for natural radioactivity. The conversion equation is:

$$
E(1 m)=\frac{[G C(A)-B]}{1553} \cdot e^{0.00587 A}
$$

where

$$
\begin{aligned}
E(\operatorname{lm})= & \text { exposure rate extrapolated to } 1 \mathrm{~m} \\
& \mathrm{AGL}(\mu \mathrm{R} / \mathrm{h}) \\
A= & \text { altitude in meters } \\
G C(A)= & \text { gross count rate at altitude } A \text { (cps) } \\
B= & \text { cosmic, aircraft,and radon back- } \\
& \text { ground (cps) }
\end{aligned}
$$

$B$ is obtained from flights over bodies of water where the terrestrial count rate is absent.

The gross count has been used for many years in the aerial system as a measure of exposure. Its simplicity yields a rapid assessment of the gamma environment.

Anomalous or nonnatural gamma sources are found from increases in the gross count rate over the natural count rates. However, subtle anomalies are difficult to find using the gross count rate in areas where its magnitude varies with, for example, geologic or ground cover changes. Differential energy data reduction methods, as discussed in the next section, are used to increase sensitivity of the aerial system to anomalous gamma emitters.

\section{B.2 SPECTRAL WINDOWS}

The aerial system produces a gamma energy spectrum each second from which the GC is computed. Generally, the ratio of natural components in any two integral sections (windows) of the energy spectrum will remain nearly constant in any given area:

$$
\sum_{E=a}^{b} E S / \sum_{E=b}^{c} E S=\text { Constant }=K
$$

$$
\begin{aligned}
& \text { where } \\
& \qquad \begin{aligned}
E S & =\text { energy spectrum } \\
E & =\text { energy } \\
a & <b<c
\end{aligned}
\end{aligned}
$$

The window, $a-b$, is placed where gamma rays from a man-made emitter would occur in the spectrum. The result of Equation B-3 could be expected to increase over the constant value, when anomalous 
gammas appear in window $a-b$. Equation $\mathrm{B}-4$ is routinely applied in the data reduction software when a search is made for specific isotopes.

$$
S=\sum_{E=a}^{b} E S-K \sum_{E=b}^{c} E S
$$

In this equation, $K$ is defined in Equation B-3 and its value is determined over a region which does not contain the man-made emitter. The net signal, $S$, is zero unless anomalous gamma rays are measured in the window defined by $a$ and $b$. A window arrangement is illustrated in Figure B-1.

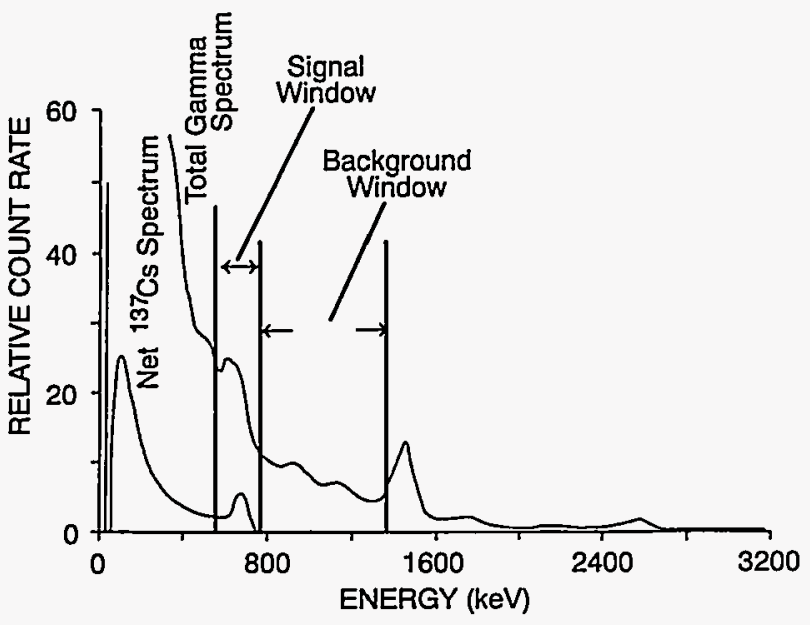

FIGURE B.1. ENERGY WINDOW SET FOR CESIUM-137 PHOTOPEAK EXTRACTION

Equation B-4 is used to locate specific isotopes by setting $a$ and $b$ to enclose the photopeak of the particular gamma from the isotope. For the general case when any man-made isotope is sought, $a, b$, and $c$ are set at $38 \mathrm{keV}, 1,394 \mathrm{keV}$, and $3,026 \mathrm{keV}$, respectively. Because most long-lived, man-made isotopes emit gammas in the energy range $38 \mathrm{keV}$ to $1,394 \mathrm{keV}$, Equation B-4 becomes a general search tool and is called the man-made gross count (MMGC).

\section{B.3 ISOTOPE CONCENTRATION COMPUTATION}

An estimate of a specific isotopic concentration in the soil may be computed from the isotope's photopeak count rate in the detector. In addition, a knowledge of the detector's basic probability for total gamma absorption, the isotopic vertical concentration distribution in the soil, and both the air and soil densities are required. The equation that approximates the photopeak count rate to isotope activity concentration is:

$$
S_{v}^{0}=\left[\frac{A_{0}}{2} \int_{0}^{\frac{\pi}{2}} \frac{R(\theta) \tan \theta e^{-(\mu / \rho)_{a} \rho_{a} h \sec \theta} d \theta}{\alpha+(\mu / \rho)_{s} \rho_{s} \sec \theta}\right]^{-1}
$$

where

$$
\begin{aligned}
& S_{v}^{0}=\text { activity per volume at the soil surface per } \\
& \text { photopeak count per second } \\
& \left(\gamma / \mathrm{sec} / \mathrm{cm}^{3} / \mathrm{cps}\right) \\
& A_{0}=\text { effective area or probability of total } \\
& R(\theta)=\text { relative detector response as a function } \\
& \text { of incident gamma angle, } \theta \text {, with respect } \\
& \text { to the vertical } \\
& \mu / \rho=\text { gamma mass attenuation coefficient } \\
& \left(\mathrm{cm}^{2} / \mathrm{g}\right) \text { in air }(a) \text { or soil }(\mathrm{s}) \\
& \rho=\text { air or soil density }\left(\mathrm{g} / \mathrm{cm}^{3}\right) \\
& a=\text { vertical concentration distribution } \\
& \text { parameter in the equation } \\
& h=\text { distance of detector above the ground } \\
& \text { (cm) } \\
& S=S_{v}^{0} e^{-a z}
\end{aligned}
$$

where $\mathbf{z}$ is the depth in soil. 


\section{REFERENCES}

1. Szasz, M. The Day the Sun Rose Twice. University of New Mexico Press, Albuquerque, New Mexico, 1984.

2. Hansen, W.R., and J.C. Rodgers. Radiological Survey and Evaluation of the Fallout Area from the Trinity Test: Chupadera Mesa and White Sands Missile Range, New Mexico, LA-10256-MS, UC-11. LANL, Los Alamos, New Mexico, 1985.

3. Quinn, V.E. Analysis of Nuclear Test Trinity Radiological and Meteorological Data, NV0-313. DOE/NV, Las Vegas, Nevada, 1987.

4. Douglas, R.L. Levels and Distribution of Environmental Plutonium Around the Trinity Site, ORP-78-3. EPA, Office of Radiation Programs, Las Vegas, Nevada, 1978.

5. Mohr, R.A., A.E. Fritzsche, and L.A. Franks. Ground Survey Procedures, Report No. EGG-1183-2339, S-635-R. EG\&G/EM, Santa Barbara, California, 1976.

6. Currie, L.A. "Limits of Qualitative Detection and Quantitative Determination." Analytic Chemistry, Vol. 40, No. 3, 1968.

7. Beck, H.L., J. DeCampo, and C. Gogolak. In Situ Ge(Li) and NaI(Tl) Gamma-Ray Spectrometry, Report No. HASL-258, TID-4500. USAEC Health and Safety Laboratory, New York, New York, 1972.

8. Mohr, R.A. Trinity Site Ground Truth Data, Letter Report RM-92-200. EG\&G/EM, Las Vegas, Nevada, 1992.

9. Mohr, R.A., and W.M. Quam. "Low Background Ge(Li) Detector Gamma Ray Spectroscopy System with Sample Changer," Proceedings of a Symposium on Remote Sensing Technology in Support of the United States Department of Energy, Report No. EGG-10282-1057. EG\&G/EM, Las Vegas, Nevada, 1985. 


\section{DISTRIBUTION}

DOE/DP

L. E. Gordon-Hagerty (1)

O.W. Taylor

(1)

DOE/HQ

OSTI

DOE/NSIC

R.S. Scott

(3)

DOE/NV

M.R. Dockter

C. A. Santilli

(1)

(1)
DOE/AL

C. L. Soden

(1)

EG\&G/EM

J. F. Doyle

LVAO

A. E. Fritzsche LVAO

G.R. Shipman WAMO

(1)

(1)

(1)

W.J. Tipton LVAO

(1)

P. H. Zavattaro

LVAO

(1)

\section{LIBRARIES}

RSL

TIC

WAMO

(30)

(1)

(1)

AN AERIAL RADIOLOGICAL SURVEY OF THE TRINITY FALLOUT AREA

WHITE SANDS MISSILE RANGE, NEW MEXICO EGG 11265-1037

DATE OF SURVEY: MAY-JUNE 1992

DATE OF REPORT: SEPTEMBER 1994 